\title{
The Equity and Efficacy of Antibiotics Altered by Food Consumption
}

\author{
Jillian Huff, Tiara Hood, Quincey Lambert, Melanie Shipe, and Sarah E. \\ Ruffell
}

University of Pittsburgh Bradford, Division of Biological and Health Sciences, 300 Campus Dr, Bradford PA 16701 USA (jch93@pitt.edu; tdh33@pitt.edu; qml3@pitt.edu; mks95@pitt.edu; ruffell@pitt.edu)

\begin{abstract}
A major challenge in the healthcare industry is that patients incorrectly use their medications. Research has shown that this behavior can sometimes be associated with language, financial limitations, and culture. The purpose of this exercise was to demonstrate the significant role these barriers have on correct use of medications, and the impact of equity in changing this behavior. This exercise is designed for student participation in groups of two and requires two days to complete, not including preparation.
\end{abstract}

Keywords: antibiotic, penicillin, effectiveness, equity

\section{Mission, Review Process \& Disclaimer}

The Association for Biology Laboratory Education (ABLE) was founded in 1979 to promote information exchange among university and college educators actively concerned with teaching biology in a laboratory setting. The focus of ABLE is to improve the undergraduate biology laboratory experience by promoting the development and dissemination of interesting, innovative, and reliable laboratory exercises. For more information about ABLE, please visit http://www.ableweb.org/.

Advances in Biology Laboratory Education is the peer-reviewed publication of the conference of the Association for Biology Laboratory Education. Published articles and extended abstracts are evaluated and selected by a committee prior to presentation at the conference, peer-reviewed by participants at the conference, and edited by members of the ABLE Editorial Board. Published abstracts are evaluated and selected by a committee prior to presentation at the conference.

\section{Citing This Article}

Huff J, Hood T, Lambert Q, Shipe M, Ruffell SE. 2020. The equity and efficacy of antibiotics altered by food consumption. Article 38 In: McMahon K, editor. Advances in biology laboratory education.Volume 41. Publication of the 41st Conference of the Association for Biology Laboratory Education (ABLE). https://doi.org/10.37590/able.v41.abs38

Compilation (C) 2020 by the Association for Biology Laboratory Education, ISBN 1-890444-17-0. All rights reserved. No part of this publication may be reproduced, stored in a retrieval system, or transmitted, in any form or by any means, electronic, mechanical, photocopying, recording, or otherwise, without the prior written permission of the copyright owner.

ABLE strongly encourages individuals to use the exercises in this volume in their teaching program. If this exercise is used solely at one's own institution with no intent for profit, it is excluded from the preceding copyright restriction, unless otherwise noted on the copyright notice of the individual chapter in this volume. Proper credit to this publication must be included in your laboratory outline for each use; a sample citation is given above. 